\title{
Acidosis during Early Reperfusion Prevents Myocardial Stunning in Perfused Ferret Hearts
}

Masafumi Kitakaze, Myron L. Weisfeldt, and Eduardo Marban

Division of Cardiology, Department of Medicine, The Johns Hopkins University School of Medicine, Baltimore, Maryland 21205

\begin{abstract}
Cellular calcium overload figures prominently in the pathogenesis of the contractile dysfunction observed after brief periods of ischemia (myocardial stunning): Because acidosis is known to antagonize $\mathrm{Ca}$ influx and the intracellular binding of $\mathrm{Ca}$, we reasoned that acidosis during reperfusion might prevent $\mathrm{Ca}$ overload and ameliorate functional recovery. We measured developed pressure (DP) and ${ }^{31} \mathrm{P}$-nuclear magnetic resonance spectra in $\mathbf{2 6}$ isovolumic Langendorff-perfused ferret hearts. After $15 \mathrm{~min}$ of global ischemia, hearts were reperfused either with normal solution ( $2 \mathrm{mM}$ [Ca] , Hepes-buffered, pH 7.4 bubbled with $100 \% \mathrm{O}_{2} ; n=6$ ) or with acidic solutions (pH 6.6 during 0-3 min, pH 7.0 during 4-6 min) before returning to the normal perfusate $(n=7)$. Ventricular function after $30 \mathrm{~min}$ of reperfusion was much greater in the acidic group (105 \pm 5 mmHg at $\left.2 \mathrm{mM}[\mathrm{Ca}]_{0}\right]$ than in the unmodified reperfusion group (79 $\pm 7 \mathrm{mmHg}, P<0.001$ ); similar differences in DP were fqund over a broad range of $[\mathrm{Ca}]_{0}(0.5-5 \mathrm{mM}, P<0.001)$ and during maximal $\mathrm{Ca}^{2+}$ activation $(\boldsymbol{P}<0.001)$. Intramyocardial $\mathrm{pH}\left(\mathrm{pH}_{\mathrm{i}}\right)$ was lower in the acidic group than in the unmodified group during early reperfusion, but not at steady state. Phosphate compounds were comparable in both groups. To clarify whether the protective effect of acidosis is due to intracellular or extracellular $\mathbf{p H}$, we produced selective intracellular acidosis during early reperfusion by exposure to $10 \mathrm{mM}$ $\mathrm{NH}_{4} \mathrm{Cl}$ for $6 \mathrm{~min}$ just before ischemia $(n=6)$. For the first 12 min of reperfusion with $\mathrm{NH}_{4} \mathrm{Cl}$-free solution $(\mathrm{pH}=7.4), \mathrm{pH}_{\mathrm{i}}$ was decreased relative to the unmodified group. Recovery of DP was practically complete, and maximal $\mathrm{Ca}^{2+}$-activated pressure was comparable to that in a nonischemic control group $(n=5)$. These results indicate that transient intracellular acidosis can prevent myocardial stunning, presumably owing to a reduction of $\mathrm{Ca}$ influx into cells and/or competition of $\mathrm{H}^{+}$for intracellular $\mathrm{Ca}^{2+}$ binding sites during early reperfusion.
\end{abstract}

\section{Introduction}

Even if ischemic heart muscle is reperfused before irreversible injury can occur, contractile function remains impaired for

A preliminary report of this study was presented at the 60th Scientific Sessions of the American Heart Association, Anaheim, CA, November 1987.

Dr. Kitakaze's permanent address is Division of Cardiology, First Department of Medicine, Osaka University School of Medicine, Osaka, Japan.

Received for publication 7 December 1987 and in revised form 11 March 1988.

J. Clin. Invest.

(c) The American Society for Clinical Investigation, Inc.

0021-9738/88/09/0920/08 $\$ 2.00$

Volume 82, September 1988, 920-927 long periods, a phenomenon known as myocardial stunning $(1,2)$. Several lines of evidence support the hypothesis (3-6) that cellular $\mathrm{Ca}$ overload during reperfusion constitutes a major cause of myocardial stunning. It has long been recognized that an increase in total tissue Ca content occurs with reperfusion after ischemia $(3,4,7-14)$. We $(9,13,14)$ and others (10) have shown that cytosolic free $\mathrm{Ca}$ levels increase markedly during 10-20 min of ischemia, and recently we have found that $\left[\mathrm{Ca}^{2+}\right]_{i}$ remains elevated during the first $5 \mathrm{~min}$ of reperfusion (13). Changes in fluorescence during ischemia have recently been interpreted as evidence for an increase in both diastolic $\left[\mathrm{Ca}^{2+}\right]_{\mathrm{i}}$ and in the amplitude of $\left[\mathrm{Ca}^{2+}\right]_{\mathrm{i}}$ transients in perfused hearts loaded with the $\mathrm{Ca}^{2+}$ indicator indo-1 (15). A pathogenetic link between cellular $\mathrm{Ca}$ overload during reflow and stunning is suggested by the observation that reperfusion with low-Ca solutions improves functional recovery after $15 \mathrm{~min}$ of ischemia in the Langendorff-perfused ferret heart (5). Calcium overload may even lead to "stunning" in the absence of ischemia and reperfusion: we have recently observed that transient $\mathrm{Ca}$ overload without ischemia leaves behind contractile dysfunction which closely mimics stunned myocardium (6). These results suggest that maneuvers designed to reduce $\mathrm{Ca}$ loading during reperfusion may help improve functional recovery.

One particularly promising intervention is acidosis, which is known to blunt $\mathrm{Ca}^{2+}$ influx into cells and $\mathrm{Ca}^{2+}$ binding to a number of high- and low-affinity intracellular sites. $\mathrm{H}^{+}$inhibits $\mathrm{Na}-\mathrm{Ca}$ exchange $(16,17)$, slow inward $\mathrm{Ca}$ channels (18-20), $\mathrm{Ca}^{2+}$ release from the sarcoplasmic reticulum $(21,22)$, and binding of $\mathrm{Ca}^{2+}$ to troponin $\mathrm{C}(22-24)$ and to sarcolemmal phospholipids (25). Perhaps as a consequence of the decrease in $\mathrm{Ca}^{2+}$ binding to intracellular sites, the $\mathrm{Ca}^{2+}$ transient that underlies excitation-contraction coupling is increased by acidosis $(26,27)$. Considerable attention has already been focused on the effects of acidosis during hypoxia or ischemia. As early as 1973, Bing and co-workers (28) found that acidosis during hypoxia improved functional recovery upon reoxygenation, as confirmed and extended by other investigators (29-31). The effects of acidosis on function have also been investigated during ischemia (32), but not upon reperfusion. Intracellular acidosis due to lactate accumulation can be quite severe during ischemia, but intramyocardial $\mathrm{pH}$ recovers very quickly afterwards (5). If $\mathrm{pH}_{\mathrm{i}}$ is restored to normal before other ionic gradients (particularly that for sodium) can reequilibrate, $\mathrm{Ca}$ influx is augmented and $\mathrm{Ca}$ binding to intracellular sites is potentiated, setting the stage for Ca-mediated reperfusion injury $(3,33)$. On the other hand, if acidosis is purposely induced during the very early reperfusion period, it may be possible to attenuate $\mathrm{Ca}$ influx and/or $\mathrm{Ca}$ binding and thereby protect against myocardial stunning.

To test the idea that acidosis might protect against stunning, we measured basic parameters of mechanical function in ferret hearts (myocardial responsiveness to $\mathrm{Ca}^{2+}$ and maximal $\mathrm{Ca}^{2+}$-activated pressure [34]). After $15 \mathrm{~min}$ of ischemia, hearts 
were initially reperfused with acidic solution before returning to solution of normal $\mathrm{pH}$. To examine selectively the effect of intracellular acidosis during reperfusion, hearts were exposed to $\mathrm{NH}_{4} \mathrm{Cl}$ just before ischemia, then reperfused with normal solution. We used phosphorus-31 nuclear magnetic resonance (NMR) ${ }^{1}$ to measure intracellular $\mathrm{pH}$ and to examine the relationship between mechanical deterioration and loss of highenergy phosphates after reperfusion.

\section{Methods}

Preparation. The experimental preparation has been described previously $(5,34,35)$. In brief, hearts were excised from 11-14-wk-old ferrets anesthetized with sodium pentobarbital $(200 \mathrm{mg}$, intraperitoneal injection), and retrogradely perfused with $100 \% \mathrm{O}_{2}$-bubbled modified Tyrode's solution. The perfusate contained (in millimolar) 108 $\mathrm{NaCl}, 5 \mathrm{KCl}, 1 \mathrm{MgCl}_{2}, 5$ Hepes, $2 \mathrm{CaCl}_{2}, 20 \mathrm{Na}$ acetate, and 10 glucose. The $\mathrm{pH}$ of the solution was normally adjusted with $\mathrm{NaOH}$ to 7.40 at $37^{\circ} \mathrm{C}$. To make the perfusate acidic ( $\mathrm{pH}=6.6$ or 7.0 ), we added concentrated $\mathrm{HCl}$ as necessary. The coronary flow rate was controlled by a peristaltic pump and was initially adjusted so that the coronary pressure equaled $90 \mathrm{mmHg}$, after which the flow rate was kept constant throughout the experiment except during global ischemia (induced by stopping the pump and clamping the perfusion line). The heart was paced at $170-190$ beats/min with a model S44 stimulator (Grass Instrument Co., Quincy, MA). A thin latex balloon tied to the end of a polyethylene tube was inserted into the left ventricle through the mitral valve and connected to a Statham P23DB pressure transducer (Gould Inc., Cleveland, $\mathrm{OH}$ ). The balloon was filled with aqueous solution to achieve an initial end-diastolic pressure of $8-12 \mathrm{mmHg}$, then kept isovolumic throughout the experiment. Perfusion pressure was monitored at the tip of the aortic cannula. Left ventricular (LV) pressure and coronary perfusion pressure were recorded with a chart recorder (Gould Inc., Cleveland, $\mathrm{OH}$ ) and an FM instrumentation tape recorder (Hewlett-Packard Inc., Palo Alto, CA).

$C a_{o}$ responsiveness and maximal $\mathrm{Ca}^{2+}$-activated pressure. We measured fundamental parameters of $\mathrm{Ca}^{2+}$-activated contraction as defined previously $(34,35)$. The responsiveness of myocardium to changes in extracellular $\mathrm{Ca}$ concentration $\left([\mathrm{Ca}]_{0}\right)$ was determined by measuring the isovolumic left ventricular developed pressure (DP) during twitch contractions as a function of $[\mathrm{Ca}]_{\mathrm{o}}(0.5,1.0,2.0,5.0$ $\mathrm{mM}$ ). All measurements were bracketed by exposure to $2 \mathrm{mM}[\mathrm{Ca}]_{0}$ solution to ascertain the stability of cardiac function. To avoid $\mathrm{Ca}$ paradox or Ca overload, [Ca] $]_{\text {o }}$ was restored to $2 \mathrm{mM}$ as soon as DP reached steady state at each $[\mathrm{Ca}]_{0} . \mathrm{Ca}_{0}$ responsiveness was determined at the beginning of each experiment and once again $30 \mathrm{~min}$ after the appropriate intervention.

Maximal $\mathrm{Ca}^{2+}$-activated pressure (MCAP) was determined from the saturating level of DP during tetani as $[\mathrm{Ca}]_{0}$ was increased (34). After the second determination of $\mathrm{Ca}_{\mathbf{o}}$ responsiveness, hearts were exposed for 10-20 min to ryanodine ( $3 \mu \mathrm{M}$; Penick Corp., Lyndhurt, $\mathrm{NJ}$ ), after which tetani were produced by high-frequency electrical stimulation $(8-12 \mathrm{~Hz})$. [Ca $]_{0}$ was increased progressively to 10,15 , and $20 \mathrm{mM}$ to obtain the saturation of DP with respect to [Ca] during tetani. The greatest value of DP during each tetanus was determined, and saturation was inferred when the values at two or more distinct $[\mathrm{Ca}]_{\mathrm{o}}$ agreed within $5 \%$.

${ }^{31}$ P-NMR measurements. In 24 of the 26 hearts studied, ${ }^{31} \mathrm{P}-\mathrm{NMR}$ spectra were obtained along with simultaneous recordings of ventricular pressure. The ${ }^{31} \mathrm{P}-\mathrm{NMR}$ methods have been reported (5). In brief, ${ }^{31} \mathrm{P}-\mathrm{NMR}$ spectra were produced on a model WH-180 spectrometer (Bruker Instruments, Inc., Billerica, MA) with a wide-bore 4.2 Tesla superconducting magnet $\left({ }^{31} \mathrm{P}\right.$ resonance frequency $\left.=72.89 \mathrm{MHz}\right)$

1. Abbreviations used in this paper: DP, developed pressure; MCAP, maximal $\mathrm{Ca}^{2+}$-activated pressure; NMR, nuclear magnetic resonance; $\mathrm{PCr}$, phosphocreatine; $\mathrm{P}_{\mathrm{i}}$, inorganic phosphate. operated in the pulsed Fourier transform mode. Spectra were obtained at a spectral width of $3 \mathrm{kHz}$ using $45^{\circ}$ pulses delivered at 2-s intervals. Exponential multiplication equivalent to $15-\mathrm{Hz}$ line broadening was applied to smooth the spectrum. The balloon in the left ventricle was filled with a $15 \mathrm{mM}$ solution of magnesium trimetaphosphate as a standard. The amounts of inorganic phosphate $\left(\mathrm{P}_{\mathrm{i}}\right)$, phosphocreatine $(\mathrm{PCr})$, and ATP in the myocardium were obtained by planimetry of the areas under individual peaks using a digitizer (model 9810A, HewlettPackard Co., Palo Alto, CA). Tissue contents of $P_{i}, P C r$, and ATP were normalized by the area under the peak for the magnesium trimetaphosphate standard. The calculated amounts of $P_{i}, P C r$, and ATP were divided by the measured weight of each heart to yield concentrations $\left(\left[\mathrm{P}_{\mathrm{i}}\right],[\mathrm{PCr}]\right.$, and $\left.[\mathrm{ATP}]\right)$ in units of micromole per gram wet weight. Intramyocardial $\mathrm{pH}\left(\mathrm{pH}_{\mathrm{i}}\right)$ was estimated from the chemical shift of the Pi peak measured relative to the resonance of $\mathrm{PCr}(36)$.

Experimental protocols. In all experiments, $\mathrm{Ca}_{0}$ responsiveness was measured before and after $20 \mathrm{~min}$ of normal perfusion, $15 \mathrm{~min}$ of ischemia, and $30 \mathrm{~min}$ of reperfusion (or a nonischemic period of equal duration). After the second determination of $\mathrm{Ca}_{\mathrm{o}}$ responsiveness, MCAP was measured in each heart as described above. The hearts were then removed from the perfusion column, blotted, and weighed. The experiments were divided into four protocols: nonischemic control $(n$ $=5$ ), unmodified reperfusion $(n=6)$, acidic reperfusion $(n=7)$, and $\mathrm{NH}_{4} \mathrm{Cl}$ washout $(n=6)$. The nature of each intervention, its rationale, and its timing are presented in detail in the Results.

Statistical analysis. All data were expressed as means \pm SE. Statistical analysis was performed with paired or unpaired $t$ tests, and multivariate analysis of variance to compare $\mathrm{Ca}_{0}$ responsiveness and changes in $\mathrm{pH}_{\mathrm{i}}$ during early reperfusion in the different experimental groups $(37,38)$.

\section{Results}

Improved recovery of function with acidic reperfusion. Fig. 1 shows developed pressure (means $\pm \mathrm{SE}$ ) as a function of time in three distinct experimental groups: $(A) 15 \mathrm{~min}$ of ischemia, then reperfusion with unmodified solution; $(B)$ the same duration of ischemia followed by reperfusion with acidic solution; and $(C)$ isochronal controls subjected transiently to acidosis without ischemia. Note that functional recovery in Fig. $1 A$ is incomplete when hearts $(n=6)$ are reperfused with unmodified solution after $15 \mathrm{~min}$ of ischemia. We have previously shown that such contractile dysfunction is associated with little evidence of histologic injury (5) and therefore qualifies as stunned myocardium.

In contrast to the persistent decrease in contractile pressure with unmodified reperfusion, Fig. $1 B$ shows virtually complete recovery of function in a group of hearts $(n=7)$ transiently reperfused with acidic solutions before returning to normal solution. The changes of solution $\mathrm{pH}$ in this protocol are depicted above the pressure data: hearts were reperfused with $\mathrm{pH}=6.6$ for the first $3 \mathrm{~min}$ and $\mathrm{pH}=7.0$ for another 3 min before returning to normal $\mathrm{pH}$ (7.4). As compared with the unmodified reperfusion group, functional recovery is significantly improved $(P<0.001)$. The dramatic preservation of function in this group agrees with our prediction that acidosis during the first moments of reperfusion might attenuate stunning.

We verified that transient acidity itself did not produce persistent changes in function by subjecting five hearts to the protocol shown in Fig. $1 C$. The hearts were perfused with acidic solutions at the same time as in $B$, but were never made ischemic. Although perfusion with solutions of low $\mathrm{pH}$ acutely decreased DP $(29,39)$, no change was apparent at steady state after returning to normal solution. This observation indicates 
A

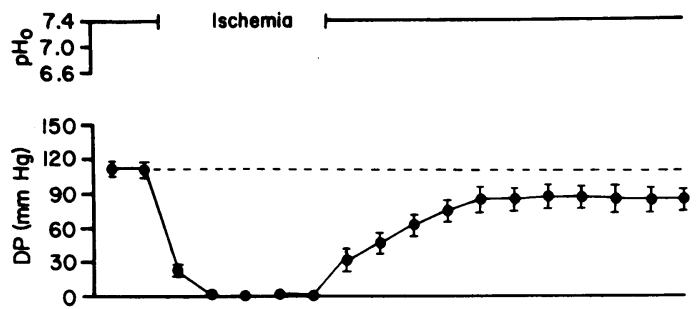

B
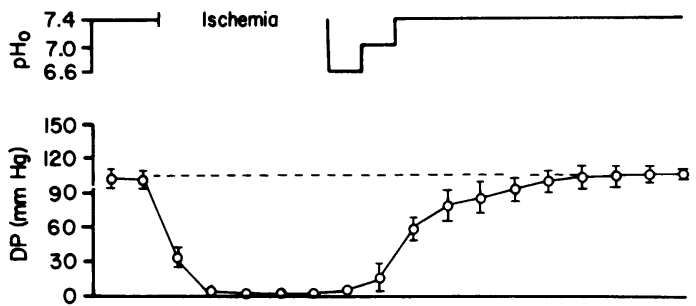

C
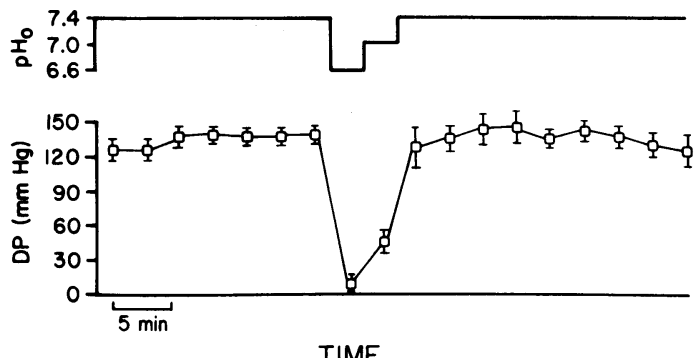

TIME

Figure 1. Ventricular function as a function of time in three experimental groups. Extracellular pH is indicated above the data for DP (means $\pm \mathrm{SE}$ ) in each protocol. $(A)$ Results from the unmodified reperfusion group; $(B)$ results from the acidic reperfusion group; and $(C)$ results from the nonischemic controls (which were never ischemic but were exposed to the same acidic solutions as in $B)$. $(A)$ After 15 min of global ischemia, DP recovers to $68 \pm 4 \%$ of its initial value in $2 \mathrm{mM}[\mathrm{Ca}]_{\mathrm{o}}$. (B) Hearts reperfused with low $\mathrm{pH}$ solutions (pH 6.6 for 0-3 min, then $\mathrm{pH} \mathrm{7.0} \mathrm{for} \mathrm{4-6} \mathrm{min}$ ) before return to $\mathrm{pH}$ 7.4 show a marked improvement in recovery (to $95 \pm 2 \%$ of DP before ischemia). (C) Hearts transiently perfused with low pH solution with the same timing as in the acidic reperfusion protocol but without ischemia show no sustained impairment of function.

that the beneficial effect of transient acidity during reperfusion is not an aftereffect of low $\mathrm{pH}$ per se.

According to the rationale for our experiments with acidic reperfusion, we would predict that the extracellular acidity blunts the rate at which $\mathrm{pH}_{\mathrm{i}}$ returns to normal after ischemia. We tested this idea by measuring $\mathrm{pH}_{\mathrm{i}}$ using ${ }^{31} \mathrm{P}-\mathrm{NMR}$. Fig. 2 shows $\mathrm{pH}_{\mathrm{i}}$ during late ischemia and early reperfusion in the unmodified group $(\bullet)$ and in the acidic group $(O)$. While the extent of acidosis at the end of the ischemic period is comparable, the two groups clearly diverge during the critical early phase $(0-12 \mathrm{~min})$ of reperfusion $(P<0.01)$. The difference in $\mathrm{pH}_{\mathrm{i}}$ is attributable to the extracellular acidification: $\mathrm{pH}_{\mathrm{i}}$ converges in the two groups after $9 \mathrm{~min}$ of reperfusion, shortly after external $\mathrm{pH}$ is restored to normal.

Contractile parameters in unmodified and acidic reperfusion. Stunned myocardium is characterized by impaired pressure development during twitch contractions over a wide range of $[\mathrm{Ca}]_{o}$ and by a decrease in MCAP (5). We sought to determine whether the beneficial effect of acidic reperfusion might be restricted to one or the other parameter because of

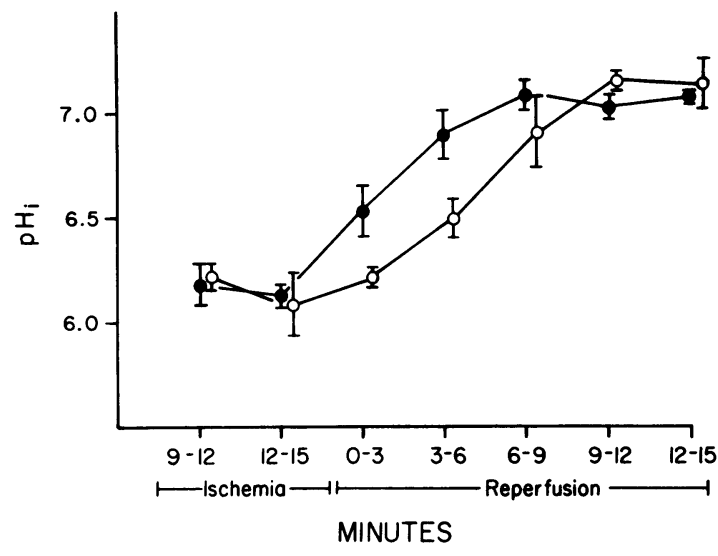

Figure 2. Intracellular pH during late ischemia and early reperfusion in the unmodified reperfusion group $(\bullet)$ and in the acidic reperfusion group (O). Although severe acidosis is observed at the end of ischemia in both groups, $\mathrm{pH}_{\mathrm{i}}$ returns to baseline more slowly $(P<0.01)$ in the acidic than in the unmodified reperfusion group. The $\mathrm{pH}_{\mathrm{i}}$ was nearly identical in both groups after 9 min of reperfusion.

differences in their mechanistic implications (34). Fig. 3 summarizes the parameters of $\mathrm{Ca}^{2+}$-activated contraction from the unmodified reperfusion $(\bullet)$, the acidic reperfusion $(O)$, and the nonischemic control ( $\square$ ) groups. Fig. $3 A$ shows developed pressure at various $[\mathrm{Ca}]_{\mathrm{o}}$ in each group $\left(\mathrm{Ca}_{0}\right.$ responsiveness). Over the range of $[\mathrm{Ca}]_{\mathrm{o}}$ from 0.5 to $5.0 \mathrm{mM}$, the force of contraction in the acidic reperfusion group was greater than in the unmodified group $(P<0.001)$, but not different from the function in the nonischemic controls $(P>0.5)$.

A similarly striking preservation of function in the acidic reperfusion group was apparent from measurements of the pressure developed during tetani after exposure of the hearts to ryanodine. Fig. $3 B$ shows that the curves of tetanic pressure and $[\mathrm{Ca}]_{\mathrm{o}}$ reach saturation at $[\mathrm{Ca}]_{\mathrm{o}} \geq 10 \mathrm{mM}$ in all three groups. The saturating pressure (i.e., MCAP) in the acidic

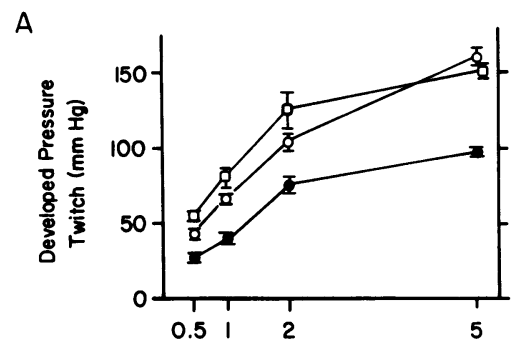

Figure 3. Characterization of contractile dysfunction in the unmodified reperfusion group (๑), acidic reperfusion group (O), and nonischemic controls ( $\square$ ). ( $A$ ) $\mathrm{Ca}_{0}$ responsiveness (DP during twitch contractions as a function of $[\mathrm{Ca}]_{0}$ ) in the unmodi-

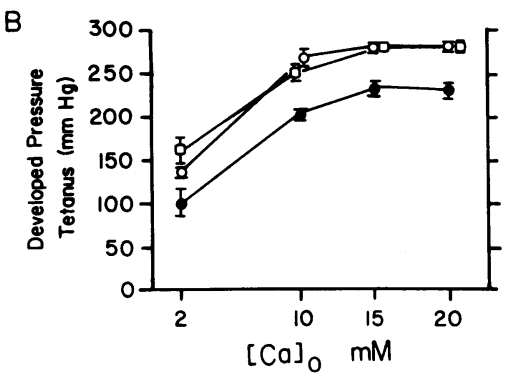
fied reperfusion group is significantly lower $(P$ $<0.001)$ than in the acidic reperfusion group. On the other hand, there is no signifcant difference between DP in the acidic reperfusion and nonischemic control groups. (B) DP during tetani in various [Ca] . MCAP is significantly higher in the acidic reperfusion group than in the unmodified group $(P<0.001)$, although no difference is observed between the acidic reperfusion and nonischemic control groups. 
group was also higher than in the unmodified reperfusion group $(281 \pm 3$ vs. $233 \pm 8 \mathrm{mmHg}, P<0.001)$. Mean MCAP in the control group equals $281 \mathrm{mmHg}$, in fortuitously exact agreement with the value in the acidic reperfusion group.

When $\mathrm{Ca}_{\mathrm{o}}$ responsiveness is normalized by the corresponding value for MCAP, the result has been termed " $\mathrm{Ca}_{0}$ sensitivity" (5). If the $\mathrm{Ca}^{2+}$ transient is unchanged in reperfused myocardium, $\mathrm{Ca}_{0}$ sensitivity is directly comparable to the true myofilament $\mathrm{Ca}^{2+}$ sensitivity as determined from the $\left[\mathrm{Ca}^{2+}\right]$-tension relation in skinned muscle. We found previously that $\mathrm{Ca}_{0}$ sensitivity is shifted to higher $[\mathrm{Ca}]_{0}$ in stunned hearts (5), and we have confirmed this in our unmodified reperfusion group (data not shown). In addition, we find that $\mathrm{Ca}_{0}$ sensitivity is unchanged in the acidic reperfusion group as compared to nonischemic controls, again indicating an improved preservation of function with acidic reperfusion. During the actual acidosis, $\mathrm{Ca}^{2+}$ transients are expected to be increased relative to normal reperfusion $(26,27)$, but a persistent aftereffect of acidosis would need to be postulated in order to explain the improved recovery evident in Fig. $3 \mathrm{~A}$ solely on the basis of changes in the $\mathrm{Ca}^{2+}$ transient.

In hearts perfused with saline solutions without blood cells or proteins, contractile dysfunction after ischemia involves not only a decrease in systolic pressure but also a rise in diastolic pressure $(5,40)$. As Table I shows, we confirmed that end-diastolic pressure was higher in the unmodified reperfusion group than in the nonischemic control hearts $(P<0.025)$. In the acidic reperfusion group, end-diastolic pressure was signifcantly lower than in the unmodified reperfusion group ( $P$ $<0.01$ ), although still somewhat elevated with respect to the nonischemic controls (Table I). This indicates that the beneficial effects of acidic reperfusion are evident in improved recovery of both systolic and diastolic function.

Acidification decreases contractile force and, although the difference in DP between the unmodified and acidic groups is small during the first 6 min of reperfusion (Fig. 1, $A$ and $B$ ), we considered the possibility that ventricular "unloading" during early reperfusion might explain the protective effect of acidosis. To check this notion, we deflated the balloon during 6 min of reperfusion in two hearts, then restored it to its previous volume. At steady state, both DP and MCAP were as low in these hearts as in the unmodified reperfusion group (DP 78 and $80 \mathrm{mmHg}, \mathrm{MCAP} 220$ and $230 \mathrm{mmHg}$ ), indicating that the protective effect of acidic reperfusion is not simply due to a decrease in ventricular work.

Table I. End-Diastolic Pressure at Various $[\mathrm{Ca}]_{o}$

\begin{tabular}{lcccc}
\hline \multicolumn{1}{c}{$[\mathrm{Ca}]_{0}(\mathrm{mM})$} & 0.5 & 1 & 2 & 5 \\
\hline & \multicolumn{5}{c}{$m m H g$} \\
Unmodified reperfusion $^{*}$ & $43.3 \pm 2.2$ & $39.0 \pm 3.0$ & $30.3 \pm 3.2$ & $25.0 \pm 2.3$ \\
Acidic reperfusion $^{\ddagger 8}$ & $30.9 \pm 5.1$ & $29.7 \pm 4.7$ & $21.4 \pm 3.1$ & $12.3 \pm 1.5$ \\
Nonischemic control $^{\prime \prime}$ & $24.3 \pm 3.6$ & $17.6 \pm 2.7$ & $13.2 \pm 2.1$ & $11.6 \pm 2.3$ \\
$\mathrm{NH}_{4} \mathrm{Cl}$ washout $^{\ddagger}$ & $19.0 \pm 4.3$ & $17.0 \pm 3.1$ & $15.3 \pm 2.2$ & $10.7 \pm 2.2$
\end{tabular}

Values given as mean $\pm \mathrm{SE}$.

${ }^{*} P<0.025,{ }^{8} P<0.001$ vs. the nonischemic control group by MANOVA.

${ }^{\|} P<0.025,{ }^{\ddagger} P<0.01$ vs. the unmodified reperfusion group by MANOVA.
Is intracellular or extracellular acidosis beneficial? The results presented above indicate that transient acidosis during reperfusion is protective, but they leave unresolved the question of whether the extracellular acidity or the secondary intracellular acidosis exerts the beneficial effect. To settle this point, we devised a new experimental strategy which results in selective intracellular acidification upon reperfusion. The key element in this strategy is exposure to $10 \mathrm{mM} \mathrm{NH}_{4} \mathrm{Cl}$ for $6 \mathrm{~min}$ just before ischemia. When the heart is reperfused with normal $\left(\mathrm{NH}_{4} \mathrm{Cl}\right.$-free, $\mathrm{pH}$ 7.4) solution, $\mathrm{NH}_{3}$ diffuses from the cell, leaving behind an acid load in the cytoplasm. Fig. 4 shows the time course of changes in DP and $\mathrm{pH}_{\mathrm{i}}$ with such a protocol in six hearts. As expected, the washout of $\mathrm{NH}_{4} \mathrm{Cl}$ upon reperfusion produced a mild intracellular acidosis (Fig. $4 \mathrm{~B}$ ) comparable to that in the acidic reperfusion group (Fig. 2) despite the fact that the $\mathrm{pH}$ of the perfusate was kept at 7.4 throughout the experiment. Fig. $4 A$ shows that the eventual recovery of DP was just as complete with this protocol as observed previously with acidic reperfusion. Similarly, end-diastolic pressure was strikingly well preserved (Table I).

The beneficial effects of $\mathrm{NH}_{4} \mathrm{Cl}$ conditioning are evident over a broad range of $[\mathrm{Ca}]_{\text {o }}$ during twitches and tetani, as shown in Fig. 5. MCAP was higher in the $\mathrm{NH}_{4} \mathrm{Cl}$ washout group than in the unmodified reperfusion group $(277 \pm 7 \mathrm{vs}$. $233 \pm 8 \mathrm{mmHg}, P<0.001$ ). The extents of recovery in $\mathrm{Ca}_{0}$ responsiveness and MCAP were identical in the acidic reper-

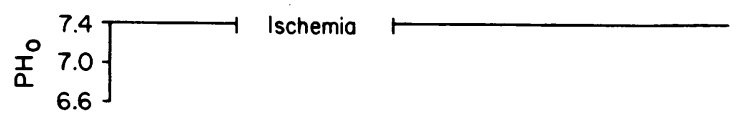

A
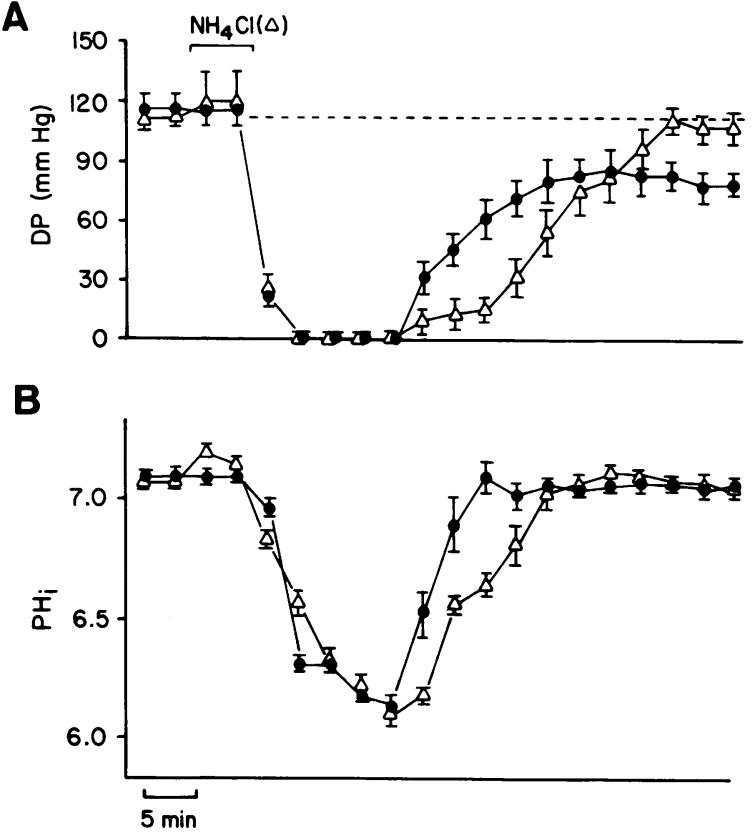

Figure 4. Effects of $6 \mathrm{~min}$ of perfusion with $10 \mathrm{mM} \mathrm{NH}_{4} \mathrm{Cl}$ before ischemia on DP and $\mathrm{pH}_{\mathrm{i}}$. Although both DP and $\mathrm{pH}_{\mathrm{i}}$ increase slightly during $\mathrm{NH}_{4} \mathrm{Cl}$ perfusion, the extents of decrease in $\mathrm{pH}_{\mathrm{i}}$ are comparable in the $\mathrm{NH}_{4} \mathrm{Cl}$ group $(\Delta)$ and in the unmodified reperfusion group (๑). Nevertheless, during early reperfusion, the intracellular acidosis resolves more slowly in the $\mathrm{NH}_{4} \mathrm{Cl}$ group. The recovery of DP in the $\mathrm{NH}_{4} \mathrm{Cl}$ group is significantly $(P<0.001)$ greater than the unmodified reperfusion group. The data for the unmodified reperfusion group overlap with those for the same group in Figs. 1 and 2. 

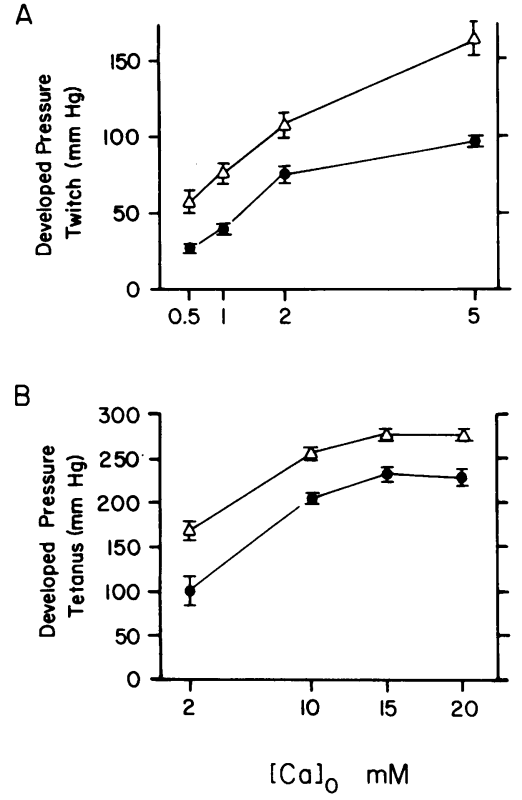

Figure 5. Characterization of contractile dysfunction in $\mathrm{NH}_{4} \mathrm{Cl}$ washout $(\Delta)$ and unmodified reperfusion ( $\bullet$ ) groups. $\mathrm{Ca}_{\mathrm{o}}$ responsiveness $(A)$ and DP during tetani $(B)$ in the $\mathrm{NH}_{4} \mathrm{Cl}$ washout group are significantly higher $(P$ $<0.01$ and $P<0.005$, respectively) than in the unmodified reperfusion group. Although omitted for clarity, the nonischemic control data is nearly superimposable upon that for the $\mathrm{NH}_{4} \mathrm{Cl}$ washout group (cf. Fig. 3). Data for unmodified reperfusion is reproduced from Fig. 3.

fusion and $\mathrm{NH}_{4} \mathrm{Cl}$ groups, indicating that intracellular acidosis is the primary factor in the protective effect of acidification during early reperfusion.

High-energy phosphate concentrations dissociated from functional recovery. An increase in either inorganic phosphate concentration $\left(\left[\mathrm{P}_{\mathrm{i}}\right]\right)$ or $\left[\mathrm{H}^{+}\right]$in myocardium has been shown to decrease maximal $\mathrm{Ca}^{2+}$-activated force and myofilament $\mathrm{Ca}^{2+}$ sensitivity in skinned papillary muscle $(22,41)$; a decrease in MCAP has been confirmed in intact hearts (35). In stunned myocardium, neither $\mathrm{pH}_{\mathrm{i}}$ nor $\left[\mathrm{P}_{\mathrm{i}}\right]$ is significantly different from the values before ischemia (5). Nevertheless, we checked whether transient intracellular acidosis leaves behind changes in $\left[\mathrm{P}_{\mathrm{i}}\right]$ or $\mathrm{pH}_{\mathrm{i}}$ by interpreting the ${ }^{31} \mathrm{P}-\mathrm{NMR}$ spectra. Fig. 6 demonstrates representative spectra from individual hearts in the unmodified reperfusion $(A)$, acidic reperfusion $(B)$, nonischemic control $(C)$, and $\mathrm{NH}_{4} \mathrm{Cl}(D)$ groups, each obtained at steady state after ischemia (or isochronally in the nonischemic control heart). The appropriate physiological peaks are labeled with the names of the corresponding phosphate species. The

calculated $\mathrm{pH}_{\mathrm{i}}$ is shown in the upper right-hand corner of each panel. Only minor variations are evident among the $\left[\mathrm{P}_{\mathrm{i}}\right]$ and $\mathrm{pH}_{\mathrm{i}}$ values in the various groups. On the other hand, [ATP] is somewhat lower in the spectra from each of the ischemia/ reperfusion groups $(A, B, D)$ as compared to the control heart $(C)$.

The findings apparent in the individual spectra in Fig. 6 are representative of the pooled data for metabolite concentrations in the various groups. Fig. 7 shows the mean values $( \pm \mathrm{SEM})$ for $\mathrm{pH}_{\mathrm{i}},[\mathrm{ATP}],\left[\mathrm{P}_{\mathrm{i}}\right]$, and $[\mathrm{PCr}]$ in each group. During initial perfusion with normal solution (labeled "Control"), the metabolite concentrations are indistinguishable in the various groups. The nonischemic control hearts ( $\square$ ), although subjected transiently to acidosis, did not develop any lasting metabolic changes throughout the experiment. In contrast, the three groups subjected to ischemia and reperfusion all exhibited qualitatively and quantitatively similar changes. The severity of ischemia in the three groups was comparable as gauged by the degrees of acidosis, PCr breakdown, and ATP depletion. At steady state during reperfusion, neither $\left[\mathrm{P}_{\mathrm{i}}\right]$ nor $\mathrm{pH}_{\mathrm{i}}$ in the three postischemic groups was significantly different from those in nonischemic controls. In contrast, [ATP] was decreased in the unmodified, acidic, and $\mathrm{NH}_{4} \mathrm{Cl}$ groups relative to the nonischemic controls $(P<0.05)$. The decrease in [ATP] was comparable in all three postischemic groups despite the marked differences in functional recovery. The observation that transient acidosis during reperfusion does not prevent ATP depletion serves as further evidence $(5,42)$ that ATP depletion is not responsible for the impairment of function in stunned myocardium.

\section{Discussion}

We have found that transient intracellular acidosis during early reperfusion prevents myocardial stunning. The beneficial effect is apparent for twitches over a range of $[\mathrm{Ca}]_{0}$ and also for maximal $\mathrm{Ca}^{2+}$-activated pressure. These observations indicate that acidotic reperfusion prevents the decrease in $\mathrm{Ca}^{2+}$ responsiveness of the contractile proteins that characterizes stunned myocardium. ATP depletion is the only identifiable metabolic sequela of ischemia in the transiently acidotic hearts, but the
A

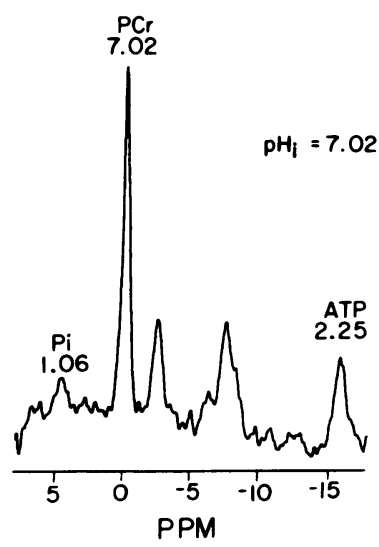

B

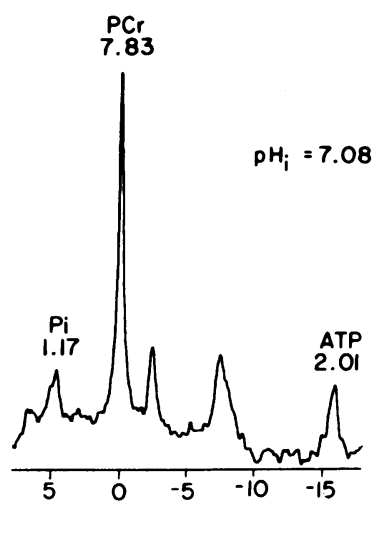

C

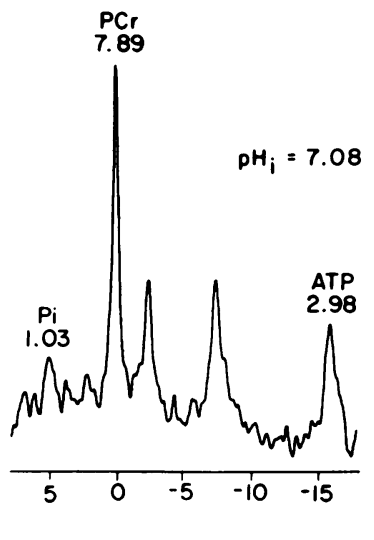

D

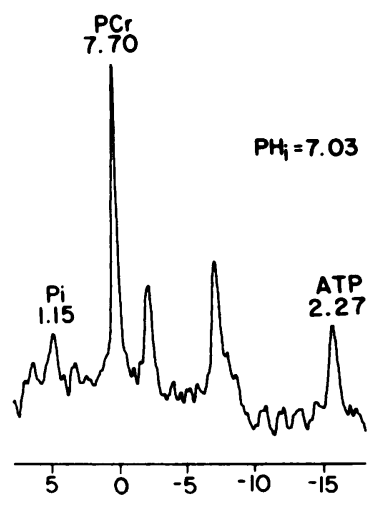

Figure 6. Representative ${ }^{31}$ P-NMR spectra (3-min acquisition time) in unmodified reperfusion $(A)$, acidic reperfusion $(B)$, nonischemic control $(C)$, and $\mathrm{NH}_{4} \mathrm{Cl}$ washout $(D)$ groups. 
$\mathrm{pH}_{\mathrm{i}}$

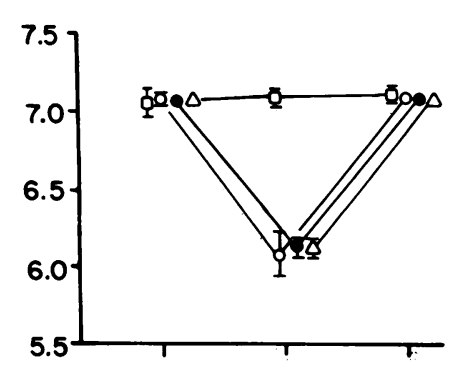

[Pi]

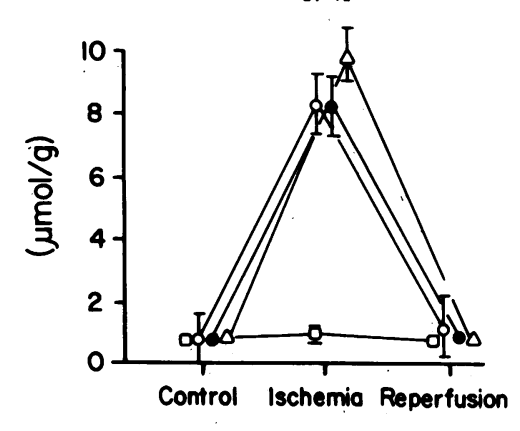

[ATP]

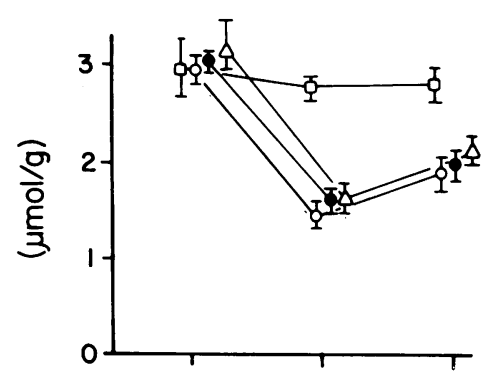

Figure 7. Intramyocardial levels of phosphate compounds and $\mathrm{pH}$ in unmodified reperfusion (๑), acidic reperfusion (O), nonischemic control ( $\square$ ), and $\mathrm{NH}_{4} \mathrm{Cl}$ washout $(\Delta)$ groups. No significant differences are observed in $\mathrm{pH}_{\mathrm{i}},\left[\mathrm{P}_{\mathrm{i}}\right]$, or $[\mathrm{PCr}]$ during baseline measurements (Control), at the end of ischemia (Ischemia) or at the new steady state after ischemia (Reperfusion) among the ischemia/reperfusion groups. Relative to the nonischemic controls, [ATP] is decreased to a comparable extent in all of the ischemia/ reperfusion groups despite the marked differences in functional recovery. extent of ATP depletion bears no relation to the degree of functional recovery.

Ca overload: cause of myocardial stunning? Several lines of evidence suggest that cellular $\mathrm{Ca}$ overload occurs during myocardial reperfusion after prolonged periods of ischemia. Shen and Jennings (7) demonstrated a gain in total $\mathrm{Ca}$ during reperfusion, as confirmed by others $(4,12)$. Measurements of ${ }^{45} \mathrm{Ca}$ accumulation have been interpreted as showing a marked increase in $\mathrm{Ca}^{2+}$ uptake during reperfusion $(8,11)$. These methods only indicate that total cellular $\mathrm{Ca}$ content (or total Ca uptake into cells) is increased during reperfusion, leaving open the question as to whether the free intracellular $\mathrm{Ca}^{2+}$ concentration, $\left[\mathrm{Ca}^{2+}\right]_{i}$, is elevated. Alternatively, most of the $\mathrm{Ca}$ gained might be bound rapidly to intracellular sites or compartmentalized (e.g., within mitochondria). Some light can be shed on this issue by recent measurements of $\left[\mathrm{Ca}^{2+}\right]_{i}$ during ischemia and reperfusion using ${ }^{19} \mathrm{~F}-\mathrm{NMR}$ and fluorinated $\mathrm{Ca}$ indicators. Steenbergen and co-workers (10) reported a fivefold increase in $\left[\mathrm{Ca}^{2+}\right]_{\mathrm{i}}$ during $10-15 \mathrm{~min}$ of ischemia in rat hearts, but no sustained increase in $\left[\mathrm{Ca}^{2+}\right]_{i}$ upon reperfusion. In ferret hearts, we have observed a significant rise in $\left[\mathrm{Ca}^{2+}\right]_{\mathrm{i}}$ during $10-20 \mathrm{~min}$ of global ischemia at $30^{\circ} \mathrm{C}(9,13$, 14), and we have also detected a sustained increase during the first $5 \mathrm{~min}$ of reperfusion (13). Taken together, the data from various techniques suggest that intracellular calcium increases during reperfusion.

A link between cellular Ca overload and stunning was first suggested by the observation that reperfusion with solutions of low [Ca] was quite effective in preserving contractile function (5). Ryanodine, an antagonist of the cytoplasmic $\mathrm{Ca}^{2+}$ oscillations that characterize $\mathrm{Ca}$ overload, has also been reported to minimize stunning (43). Recently we tested whether Ca overload might suffice to explain stunning even without invoking other features of ischemia and reperfusion. We found that ferret hearts subjected to transient $\mathrm{Ca}$ overload without ischemia develop contractile dysfunction indistinguishable metabolically and histologically from stunning (6). These various lines of evidence suggest that $\mathrm{Ca}$ overload during reperfusion plays a major, if not primary, role in the pathogenesis of stunned myocardium.

Mechanisms by which acidosis prevents intracellular $\mathrm{Ca}$ overload. During reperfusion, the principal abnormality detectable by $\mathrm{Ca}$ tracer uptake measurements has been an increase in $\mathrm{Ca}$ influx (11). The cellular consequences of augmented $\mathrm{Ca}$ influx will be greatly influenced by the extent to which $\mathrm{Ca}^{2+}$ binds to intracellular receptors such as $\mathrm{Ca}^{2+}-\mathrm{de}-$ pendent enzymes, since these presumably act as the final effectors of reperfusion injury. An increase in intracellular $\mathrm{H}^{+}$ concentration can inhibit several pathways of $\mathrm{Ca}^{2+}$ movement into cells, as well as decrease the binding of $\mathrm{Ca}$ to intracellular sites. First of all, an increase in $\left[\mathrm{H}^{+}\right]$leads to decreased $\mathrm{Ca}$ influx through voltage-dependent slow $\mathrm{Ca}$ channels (18-20). Irisawa and Sato (20) showed that effects of $\mathrm{H}^{+}$on $\mathrm{Ca}$ current are more potent at the inner surface of the cell membrane than extracellularly, consistent with our finding that intracellular acidosis is the crucial variable. Nevertheless, Ca channels probably play only a minor role in reperfusion injury, since verapamil is not protective when infused only during reperfusion (3, 11). Acidosis is also known to inhibit the release of $\mathrm{Ca}^{2+}$ from sarcoplasmic reticulum $(21,22)$; reactivation of $\mathrm{Ca}^{2+}$-induced $\mathrm{Ca}^{2+}$ release may be capable of potentiating the physiologic effects of augmented $\mathrm{Ca}$ influx, but is not likely to be the primary site of action of $\mathrm{H}^{+}$.

A more likely mediator of the effects of $\mathrm{H}^{+}$is the $\mathrm{Na}-\mathrm{Ca}$ exchange $(16,17)$, which has been implicated as the pathway primarily responsible for the increase in $\mathrm{Ca}$ influx upon reperfusion $(3,33)$. The changes in ionic gradients (increased $[\mathrm{Na}]_{i}$ and $\left.\left[\mathrm{Ca}^{2+}\right]_{i}\right)$ and in membrane potential (depolarization) that 
accompany ischemia will, if anything, tend to favor $\mathrm{Ca}$ influx via "reverse mode" $\mathrm{Na} / \mathrm{Ca}$ exchange (44). The involvement of $\mathrm{Na}-\mathrm{Ca}$ exchange is supported by the finding that reperfusion with low $\left[\mathrm{Na}^{+}\right]$solution markedly attenuates $\mathrm{Ca}$ uptake after $40 \mathrm{~min}$ of global ischemia in rat hearts (3). Similarly, functional and metabolic recovery are improved when lithium substitutes for $\mathrm{Na}$ in a low-flow ischemic perfusate (33). While acknowledging that estimates of $\mathrm{Ca}$ influx via $\mathrm{Na}-\mathrm{Ca}$ exchange are subject to various technical limitations, a number of investigators have concluded that acidosis inhibits $\mathrm{Ca}$ transport via this pathway. If $[\mathrm{Na}]_{i}$ is elevated during ischemia $(45-47$; cf. 48), then the rapid restoration of $\mathrm{pH}_{\mathrm{i}}$ to normal would be expected to increase the activity of $\mathrm{Na}-\mathrm{Ca}$ exchange and thereby drive in $\mathrm{Ca}$ upon reperfusion. By blunting the time course of $\mathrm{pH}_{\mathrm{i}}$ recovery after ischemia, reperfusion acidosis could allow the $\mathrm{Na}$ gradient more time to be restored before $\mathrm{pH}_{\mathrm{i}}$ returns to normal. The driving force for $\mathrm{Ca}$ entry upon reperfusion would thus be dissipated before $\mathrm{Na}-\mathrm{Ca}$ exchange is fully reactivated.

The possibility that acidosis might attenuate injury by decreasing the degree of intracellular $\mathrm{Ca}$ binding is rendered plausible by various observations. Direct measurements of $\left[\mathrm{Ca}^{2+}\right]_{\mathrm{i}}$ reveal a slight increase during acidosis $(26,27)$, indicating that less $\mathrm{Ca}^{2+}$ must be bound in view of the finding that $\mathrm{Ca}$ uptake is not increased by acidosis (39). A fall in $\mathrm{pH}_{\mathrm{i}}$ depresses the $\mathrm{Ca}$ binding capacity of sarcolemmal phospholipids (25) and troponin C (22-24). The precise relationship of decreased $\mathrm{Ca}$ binding to the mechanism of injury remains unclear, but candidates for effectors of injury include the $\mathrm{Ca}^{2+}$ activated protease implicated in postischemic cytoskeletal degradation (49).

\section{Acknowledgments}

We thank Dr. Hideo Kusuoka for his comments on the manuscript and for numerous helpful discussions.

This study was supported by grant HL-36957 to Dr. Marban and SCOR grant HL-17655 from the National Institutes of Health. Dr. Marban is the recipient of Research Career Development Award K04 01872 from the National Heart, Lung and Blood Institute.

\section{References}

1. Braunwald, E., and R. A. Kloner. 1982. The stunned myocardium: prolonged, postischemic ventricular dysfunction. Circulation. 60:1146-1149.

2. Braunwald, E., and R. A. Kloner. 1985. Myocardial reperfusion: a double-edged sword? J. Clin. Invest. 76:1713-1719.

3. Grinwald, P. M. 1982. Calcium uptake during post-ischemic reperfusion in the isolated rat heart: influence of extracellular sodium. J. Mol. Cell. Cardiol. 14:359-365.

4. Nayler, W. G. 1983. Calcium and cell death. Eur. Heart J. 4(Suppl. C):33-41.

5. Kusuoka, H., J. K. Porterfield, H. F. Weisman, M. L. Weisfeldt, and E. Marban. 1987. Pathophysiology and pathogenesis of stunned myocardium: depressed $\mathrm{Ca}^{2+}$ activation of contraction as a consequence of reperfusion-induced cellular calcium overload in ferret hearts. J. Clin. Invest. 79:950-961.

6. Kitakaze, M., H. F. Weisman, and E. Marban. 1988. Contractile dysfunction and ATP depletion after transient calcium overload in perfused ferret hearts. Circulation. 77:685-695.

7. Shen, A. C., and R. B. Jennings. 1972. Myocardial calcium and magnesium in acute ischemic injury. Am. J. Pathol. 67:417-440.

8. Shen, A. C., and R. B. Jennings. 1972. Kinetics of calcium accumulation in acute myocardial ischemic injury. Am. J. Pathol. 67:441-452.

9. Marban, E., M. Kitakaze, H. Kusuoka, J. K. Porterfield, D. T. Yue, and V. P. Chacko. 1987. Intracellular free calcium concentration measured with ${ }^{19} \mathrm{~F}$ NMR spectroscopy in intact ferret hearts. Proc. Natl. Acad. Sci. USA. 84:6005-6009.

10. Steenbergen, C., E. Murphy, L. Levy, and R. E. London. 1987. Elevation in cytosolic free calcium concentration early in myocardial ischemia in perfused rat heart. Circ. Res. 60:700-707.

11. Bourdillon, P. D. V., and P. A. Poole-Wilson. 1981. Effects of ischemia and reperfusion on calcium exchange and mechanical function in isolated rabbit myocardium. Cardiovasc. Res. 15:121-130.

12. Sharma, A. D., J. E. Saffitz, B. I. Lee, B. E. Sobel, and P. B. Corr. 1983. Alpha adrenergic-mediated accumulation of calcium in reperfused myocardium. J. Clin. Invest. 72:802-818.

13. Kitakaze, M., M. M. Pike, V. P. Chacko, and E. Marban. 1987. Direct measurement of cytosolic free calcium during ischemia and reperfusion in ferret hearts. Circulation. 76:IV-380. (Abstr.)

14. Pike, M. M., M. Kitakaze, V. P. Chacko, and E. Marban. 1987. Lidocaine prevents the increase in myocardial free calcium during ischemia and reperfusion. Circulation. 76:IV-16. (Abstr.)

15. Lee, H.-C., N. Smith, R. Mohabir, and W. T. Clusin. 1987. Cytosolic calcium transients from the beating mammalian heart. Proc. Natl. Acad. Sci. USA. 84:7793-7797.

16. Philipson, K. D., M. M. Bersohn, and A. Y. Nishimoto. 1982. Effects of $\mathrm{pH}$ on $\mathrm{Na}^{+}-\mathrm{Ca}^{2+}$ exchange in canine cardiac sarcolemmal vesicles. Circ. Res. 50:287-293.

17. Kim, D., E. J. Cragoe Jr., and T. W. Smith. 1987. Relation among sodium pump inhibition, $\mathrm{Na}-\mathrm{Ca}$ and $\mathrm{Na}-\mathrm{H}$ exchange activities, and $\mathrm{Ca}-\mathrm{H}$ interaction in cultured chick heart cells. Circ. Res. 60:185193.

18. Chesnais, J. M., E. Coraboeuf, M. P. Sauviat, and J. M. Vassas. 1975. Sensitivity to $\mathrm{H}, \mathrm{Li}$ and $\mathrm{Mg}$ ions of the slow inward sodium current in frog atrial fibers. J. Mol. Cell. Cardiol. 7:627-642.

19. Fry, C. H., and P. A. Poole-Wilson. 1981. Effects of acid-base changes on excitation-contraction coupling in guinea pig and rabbit cardiac ventricular muscle. J. Physiol. (Lond.). 313:141-160.

20. Irisawa, H., and R. Sato. 1986. Intra- and extracellular actions of proton on the calcium current of isolated guinea pig ventricular cells. Circ. Res. 59:348-355.

21. Nakamaru, Y., and A. Schwartz. 1972. The influence of hydrogen ion concentration on calcium binding and release by skeletal muscle sarcoplasmic reticulum. J. Gen. Physiol. 59:22-32.

22. Fabiato, A., and F. Fabiato. 1978. Effects of $\mathrm{pH}$ on myofilaments and the sarcoplasmic reticulum on skinned cells from cardiac and skeletal muscles. J. Physiol. (Lond.). 276:233-255.

23. Katz, A. M., and H. H. Hecht. 1969. The early 'pump' failure of the ischemic heart. Am. J. Med. 47:497-502.

24. Donaldson, S. K. B., and L. Hermansen. 1978. Differential, direct effects of $\mathrm{H}^{+}$on $\mathrm{Ca}^{2+}$-activated force of skinned fibers from the soleus, cardiac and adductor magnum muscle of rabbits. Pflügers Arch. Eur. J. Physiol. 376:55-65.

25. Langer, G. A. 1985. The effect of $\mathrm{pH}$ on cellular and membrane calcium binding and contraction of myocardium: a possible role of sarcolemmal phospholipid in EC coupling. Circ. Res. 57:374-382.

26. Allen, D. G., and C. H. Orchard. 1983. The effect of changes of $\mathrm{pH}$ on intracellular calcium transients in mammalian cardiac muscle. J. Physiol. (Lond.). 327:79-94.

27. Orchard, C. H. 1987. The role of sarcoplasmic reticulum in the response of ferret and rat heart muscle to acidosis. J. Physiol. (Lond.). 384:431-449.

28. Bing, O. H. L., W. W. Brooks, and J. V. Messer. 1973. Heart muscle viability following hypoxia: protective effect of acidosis. Science (Wash. DC). 180:1297-1298.

29. Greene, H. L., and M. L. Weisfeldt. 1977. Determinants of hypoxic and posthypoxic myocardial contracture. Am. J. Physiol. 232:H526-H533.

30. Lakatta, E. G., W. G. Nayler, and P. A. Poole-Wilson. 1979. 
Calcium overload and mechanical function in posthypoxic myocardium: biphasic effect of pH during hypoxia. Eur. J. Cardiol. 10:77-87.

31. Nayler, W. G., R. Ferrari, P. A. Poole-Wilson, and C. E. Yepez. 1979. A protective effect of a mild acidosis on hypoxic heart muscle. $J$. Mol. Cell. Cardiol. 11:1053-1071.

32. Weisfeldt, M. L., R. L. Bishop, and H. L. Greene. 1975. Effect of $\mathrm{pH}$ and $\mathrm{pCO}_{2}$ on performance of ischemic myocardium. In Metabolism of Contraction. Rec. Adv. Stud. Card. Struct. Metab. 10:355-364.

33. Renlund, D. G., G. Gerstenblith, E. G. Lakatta, W. E. Jacobus, C. H. Kallman, and M. L. Weisfeldt. 1984. Perfusate sodium during ischemia modifies postischemic functional and metabolic recovery in the rabbit heart. J. Mol. Cell. Cardiol. 14:795-801.

34. Marban, E., H. Kusuoka, D. T. Yue, M. L. Weisfeldt, and W. G. Wier. 1986. Maximal Ca ${ }^{2+}$-activated force elicited by tetanization of ferret papillary muscle and whole heart. Mechanism and characteristics of steady contractile activation in intact myocardium. Circ. Res. 59:262-269.

35. Kusuoka, H., M. L. Weisfeldt, J. L. Zweier, W. E. Jacobus, and E. Marban. 1986. Mechanism of early contractile failure during hypoxia in intact ferret heart: evidence of modulation of maximal $\mathrm{Ca}^{2+}$. activated force by inorganic phosphate. Circ. Res. 59:270-282.

36. Flaherty, J. T., M. L. Weisfeldt, B. H. Bulkley, T. J. Gardner, V. L. Gott, and W. E. Jacobus. 1982. Mechanisms of ischemic myocardial cell damage assessed by phosphorus-31 nuclear magnetic resonance. Circulation. 65:561-571.

37. Snedecor, G. W., and W. G. Cochran. 1980. Statistical Methods. 7th edition. Iowa State University Press, Ames, IA. 1-507.

38. Winer, B. J. 1982. Statistical Principles in Experimental Design. 2nd edition. McGraw-Hill Book Co., New York. 1-907.

39. Kim, D., and T. W. Smith. 1987. Altered Ca fluxes and contractile state during $\mathrm{pH}$ changes in cultured heart cells. Am. J. Physiol. 253:C137-C146.

40. Wexler, L. F., E. O. Weinberg, J. S. Ingwall, and C. S. Apstein. 1987. Acute alterations in diastolic left ventricular chamber distensi- bility: mechanistic differences between hypoxemia and ischemia in isolated perfused rabbit and rat hearts. Circ. Res. 59:515-523.

41. Kentish, J. C. 1986. The effects of inorganic phosphate and creatine phosphate on force production in skinned muscles from rat ventricle. J. Physiol. (Lond.). 370:585-604.

42. Ambrosio, G., W. E. Jacobus, and L. C. Becker. 1986. Effect of ATP precursof administration on post-ischemic function and metabolism in isolated rabbit hearts. J. Am. Coll. Cardiol. 7:79A. (Abstr.)

43. Porterfield, J. K., H. Kusuoka, H. F. Weisman, M. L. Weisfeldt, and E. Marban. 1987. Ryanodine prevents the changes in myocardial function and morphology induced by reperfusion after brief periods of ischemia. Clin. Res. 35:315A. (Abstr.)

44. Barcenas-Ruiz, L., D. J. Beuckelmann, and W. G. Wier. 1987. Sodium-calcium exchange in heart: membrane currents and changes in $\left[\mathrm{Ca}^{2+}\right]_{\mathrm{i}}$. Science (Wash. DC). 238:1720-1722.

45. Regan, T. J., L. Broisman, B. Haider, C. Eaddy, and H. A. Oldewurtel. 1980. Dissociation of myocardial sodium and potassium alterations in mild versus severe ischemia. Am. J. Physiol. 238:H575H580.

46. Wilde, A. A. M., and A. G. Kléber. 1986. The combined effects of hypoxia, high $\mathrm{K}^{+}$, and acidosis on the intracellular sodium activity and resting potential in guinea pig papillary muscle. Circ. Res. 58:249-256.

47. Neubauer, S., J. A. Balschi, C. S. Springer, T. W. Smith, and J. S. Ingwall. 1987. Intracellular $\mathrm{Na}^{+}$accumulation in hypoxic vs. ischemic rat heart: evidence for $\mathrm{Na}^{+}-\mathrm{H}^{+}$exchange. Circulation. 76:IV-56. (Abstr.)

48. Kléber, A. G. 1983. Resting membrane potential, extracellular potassium activity, and intracellular sodium activity during acute global ischemia in isolated perfused guinea pig hearts. Circ. Res. $52: 442-450$.

49. Steenbergen, C., M. L. Hill, and R. B. Jennings. 1987. Cytoskeletal damage during myocardial ischemia: changes in vinculin immunofluorescence staining during total in vitro ischemia in canine heart. Circ. Res. 60:478-486. 